\title{
The helix surface of sugar ring for tetrahydrofuran*
}

\author{
Jin $\mathrm{Li}^{1}$, Zhenghe $\mathrm{Zhu}^{2 \#}$ \\ ${ }^{1}$ College of Materials and Chemical Engineering, Hainan University, Haikou, China \\ ${ }^{2}$ Institutes of Atomic and Molecular Physics, Sichuan University, Chengdu, China; ${ }^{\#}$ Corresponding Author: zhuxm@scu.edu.cn
}

Received 11 January 2014; revised 11 February 2014; accepted 18 February 2014

Copyright (c) 2014 Jin Li, Zhenghe Zhu. This is an open access article distributed under the Creative Commons Attribution License, which permits unrestricted use, distribution, and reproduction in any medium, provided the original work is properly cited. In accordance of the Creative Commons Attribution License all Copyrights ¿ 2014 are reserved for SCIRP and the owner of the intellectual property Jin Li, Zhenghe Zhu. All Copyright (C) 2014 are guarded by law and by SCIRP as a guardian.

\section{ABSTRACT}

The present calculations of three geometry conformation for tetrahydrofuran (THF, $\mathrm{C}_{4} \mathrm{H}_{8} \mathrm{O}$ ) using density functional theory lead to the energy level sequence $E\left(C_{1}\right)<E\left(C_{s}\right)<E\left(C_{2 v}\right)$, where, both the geometry symmetry $C_{2 v}$ and $C_{s}$ are probably a transition structure. The $C_{1}$ symmetry is the equilibrium conformation, for its energy is the lowest one and it is only possible without the negative harmonic frequency. In $C_{1}$ conformation, the 4 of carbon atoms $C$ and oxygen atom $O$ constitute $a$ curved surface or the helix surface. The tetrahydrofuran molecule can be as a simple prototype of deoxyribose and has been reviving a quite deal of interest in radiation damage research. It is well known that the sugar ring of deoxyribose is considered as a plane in most of the references. If the equilibrium conformation of THF is $C_{1}$ symmetry with the helix surface, and for the same reason, the sugar ring of deoxyribose would be also the helix surface; this probably causes the double helix of DNA. It is hardly believed that the sugar ring is a plane in deoxyribose.

\section{KEYWORDS}

\section{Coupled Cluster; Electronic Structure; Excited States}

\section{INTRODUCTION}

Tetrahydrofuran (THF) also called diethylene oxide or oxacyclopentane is a good solvent, and the study of its structure is a current focus for it can be as a moiety of nucleosides. It is well-known that a large amount of energy deposited in living cells by ionizing radiation is chan-

*PACC numbers: 3120C; 3130; 3150. neled into the production of low-energy secondary electrons. Therefore, investigation of radiation damage in living tissue upon exposure to high-energy radiation must include and apprehend these subsequent processes describing reaction between secondary electrons and cell constitutes. The dissociation of small DNA's basic components as a function of incident energy of bombarding electrons has been shown to correlate to the measured DNA damage [1]. Being a simple prototype to investigate electron-induced decomposition of deoxyribose ring, tetrahydrofuran molecule $\left(\mathrm{C}_{4} \mathrm{H}_{8} \mathrm{O}\right)$ has revived a quite deal of interest in radiation damage research in recent years.

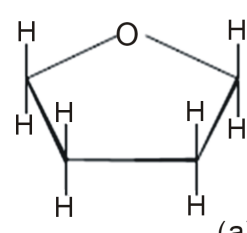

(a)

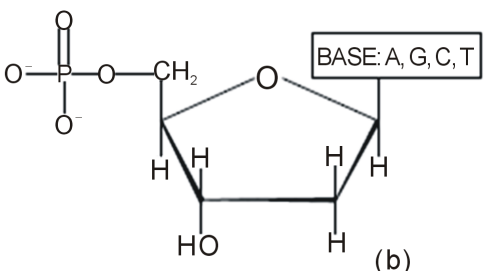

(b)
Where (a) is the tetrahydrofuran molecule $\left(\mathrm{C}_{4} \mathrm{H}_{8} \mathrm{O}\right)$, (b) is the deoxyribose ring.

Several papers on electron interaction with either gaseous or surface deposited THF have been recently published, which consider electron spectroscopy of resonance-enhanced vibration excitation [2], electron-stimulated desorption yields of $\mathrm{H}^{-}$from thin films [3,4] and electron induced damage of solid THF film [5]. The earlier work on THF has also been summarized [5].

Since the discovery of the DNA double helix in 1953 [6], the structure of tetrahydrofuran is a kind of scientific controversy, for there are various descriptions. One of equilibrium geometries of THF is a twisted $\mathrm{C}_{2}$ group, which may be a transition structure [7,8]. However, $a b$ initio calculation predicts that the equilibrium structure of THF is an envelope conformation of $C_{s}$ [9], in which 4 of carbon atoms in a plane and oxygen atom out of this 
plane. Many of the works, specially, pay attention the structure of liquid tetrahydrofuran. Hydrogen/deuterium isotopic substitution neutron diffraction techniques have been used to measure the structural correlation functions of liquid tetrahydrofuran at room temperature [10]. The molecular interactions of pyrazine with THF are the weak Hydrogen bond N-C-H...O [11]. The tetrahydrofuran clathrate hydrate rapidly densifies at $77 \mathrm{~K}$ and $\sim 1.3 \mathrm{GPa}$. The densified sample is then heated to $150 \mathrm{~K}$ at $1.5 \mathrm{Gpa}$, and recovered at 1 bar and $77 \mathrm{~K}$. Its X-ray and Raman measurements show that the densified sample is amorphous. The molecular arrangement of water in this sample appears to be similar to that in high-density amorphous ice [12].

\section{DENSITY FUNCTIONAL THEORY}

In DFT, electronic energy $E$ is divided into several components,

$$
E=E^{T}+E^{V}+E^{J}+E^{\mathrm{XC}},
$$

where $E^{T}$ is the electronic kinetic energy, $E^{V}$ is the potential energy including the electron-nucleus attraction and nucleus-nucleus repulsion, $E^{J}$ is the electron-electron repulsion, and $E^{X C}$ is the exchange-correlation. Except nucleus-nucleus repulsion, each term can be expressed as the function of electron density $\rho$

$$
\begin{gathered}
E^{J}=\frac{1}{2} \iint \rho\left(\boldsymbol{r}_{1}\right)\left(\Delta \boldsymbol{r}_{12}\right)^{-1} \rho\left(\boldsymbol{r}_{2}\right) \mathrm{d} \boldsymbol{r}_{1} \mathrm{~d} \boldsymbol{r}_{2}, \\
E^{X C}(\rho)=\int f\left(\rho_{\alpha}(\boldsymbol{r}), \rho_{\beta}(\boldsymbol{r}), \nabla \rho_{\alpha}(\boldsymbol{r}), \nabla \rho_{\beta}(\boldsymbol{r})\right) \mathrm{d}^{3} \boldsymbol{r},(3) \\
E^{X C}(\rho)=E^{X}(\rho)+E^{C}(\rho),
\end{gathered}
$$

where all the three terms are the functions of electron density. $E^{X}(\rho)$ and $E^{C}(\rho)$ are the exchange and correlation functional, respectively, the former is a local functional only related with the electron density, and the later is a gradient-corrected functional related with the electron density and its gradient $\nabla \rho$. In 1988, Becke [13] derived the local exchange functional as follows:

$$
\begin{gathered}
E_{\text {Becke88 }}^{X}=E_{\mathrm{LDA}}^{X}-\gamma \int \frac{\rho^{4 / 3} x^{2}}{\left(1+6 \gamma \sin h^{-1} x\right)} \mathrm{d}^{3} \boldsymbol{r}, \\
E_{\mathrm{LDA}}^{X}=-\frac{3}{2}\left(\frac{3}{4 \pi}\right)^{1 / 3} \int \rho^{4 / 3} \mathrm{~d}^{3} \boldsymbol{r},
\end{gathered}
$$

where $\rho$ is a function of $r, \quad x=\rho^{-4 / 3}|\nabla \rho|, \gamma$ is a parameter fitted with the exchange energy of noble atoms $(\gamma=$ 0.0042 a.u.). Similarly, in 1992, Perdew and Wang [14] suggested a corrected functional as

$$
E^{C}=\int \rho \varepsilon_{C}\left(r_{s}(\rho(\boldsymbol{r})), \zeta\right) \mathrm{d}^{3} \boldsymbol{r},
$$

where

$$
\begin{gathered}
r_{s}=\left[\frac{3}{4 \pi \rho}\right]^{1 / 3}, \zeta=\frac{\rho_{\alpha}-\rho_{\beta}}{\rho_{\alpha}+\rho_{\beta}}, \\
\varepsilon_{\mathrm{C}}\left(r_{s}, \zeta\right)=\varepsilon_{\mathrm{C}}(\rho, 0)+a_{\mathrm{C}}\left(r_{s}\right) \frac{f(\zeta)}{f^{\prime \prime}(0)}\left(1-\zeta^{4}\right) \\
+\left[\left(\varepsilon_{\mathrm{C}}(\rho, 1)-\varepsilon_{\mathrm{C}}(\rho, 0)\right)\right] f(\zeta) \zeta^{4}, \\
f(\zeta)=\frac{\left[(1+\zeta)^{4 / 3}+(1-\zeta)^{4 / 3}-2\right]}{\left(2^{4 / 3}-2\right)},
\end{gathered}
$$

Here $r_{s}$ is the density parameter and $\zeta$ is the correlated spin polarization. DFT is a joint calculation with the exchange and correlation functional. The B3LYP method is to combine Becke's exchange functional and the correlated functional of Lee, Yang and Parr, with both are gradient-corrected. The local correlation functional is from Vosko, Wilk and Nusair(VWN). Then the so-called Becke's three parameter functional [15] is

$$
\begin{aligned}
E_{\mathrm{B3LYP}}^{X C}= & E_{\mathrm{LDA}}^{X}+c_{0}\left(E_{\mathrm{HF}}^{X}-E_{\mathrm{LDA}}^{X}\right) \\
& +c_{\mathrm{X}} \Delta E_{\mathrm{B} 88}^{X}+E_{\mathrm{VWN} 3}^{C}+c_{\mathrm{C}}\left(E_{\mathrm{LYP}}^{C}-E_{\mathrm{VWN} 3}^{C}\right)
\end{aligned}
$$

Using G1 method, Becke has obtained: $c_{0}=0.20, c_{\mathrm{X}}=$ 0.72 and $c_{\mathrm{C}}=0.81$ by optimizing of exchange and correlation energy. The Eq.9 with the lower energy calculated will be used for the presented DFT-SCF calculations.

$$
\begin{aligned}
& E_{\mathrm{B} 3 \mathrm{P} 86}^{X C} \\
& =(1-a) E_{\mathrm{LDA}}^{X}+a E_{\mathrm{HF}}^{X}+b \Delta E_{\mathrm{B} 88}^{X}+(1-c) E_{\mathrm{LSDA}}^{C}+c E_{\mathrm{P} 86}^{C}
\end{aligned}
$$

\section{THE THEORETICAL DERIVATION OF MOLECULAR ELECTRONIC STATE}

The molecular electronic state is the irreducible representation of molecular group, therefore, before the calculation, it is necessary to derive the possible electronic states based on the resolution, reduction and product of group representation [16-19]. Now, we derive the possible electronic states for some of possible symmetry groups, for example, tetrahydrofuran (THF) will be possible group $\mathrm{C}_{2 \mathrm{v}}, \mathrm{C}_{\mathrm{s}}$, or $\mathrm{C}_{1}$.

For simplicity, we firstly derive the electronic state of furan $\left(\mathrm{C}_{4} \mathrm{H}_{4} \mathrm{O}\right)$, its ground state is known as $\tilde{\mathrm{X}}^{1} \mathrm{~A}_{1}$ of $\mathrm{C}_{2 \mathrm{v}}$. It is supposed that we have the following reaction

$$
\mathrm{C}_{2}\left(D_{\infty \circ}, \tilde{\mathrm{X}}^{1} \Sigma_{g}^{+}\right)+\mathrm{C}_{2}\left(D_{\infty h}, \tilde{\mathrm{X}}^{1} \Sigma_{g}^{+}\right)+\mathrm{H}_{2}\left(D_{\infty h}, \tilde{\mathrm{X}}^{1} \Sigma_{g}^{+}\right)+\mathrm{H}_{2}\left(D_{\infty h}, \tilde{\mathrm{X}}^{1} \Sigma_{g}^{+}\right)+\mathrm{O}\left({ }^{1} D_{g}\right) \rightarrow \mathrm{C}_{4} \mathrm{H}_{4} \mathrm{O}\left(\mathrm{C}_{2 \mathrm{v}}, \tilde{\mathrm{X}}^{1} \mathrm{~A}_{1}\right)
$$


All the irreducible representation for given the reactive molecules with given state are resolved into the irreducible representation of molecular group $\mathrm{C}_{2 \mathrm{v}}$ of $\mathrm{C}_{4} \mathrm{H}_{4} \mathrm{O}$, as follows. Oxygen $\mathrm{O}$ atom must be the singlet excited state ${ }^{1} D_{g}$, in order to result the singlet ground state $\tilde{\mathrm{X}}^{1} \mathrm{~A}_{1}$ of furan based on the quantization vector addition of spin. The resolution of the irreducible representation, i.e. the electronic state for 2 of $\mathrm{C}_{2}$ and 2 of $\mathrm{H}_{2}$, all are the same as

$$
\begin{gathered}
D_{\infty h}, \tilde{\mathrm{X}}^{1} \Sigma_{g}^{+} \rightarrow \mathrm{C}_{2 \mathrm{v}},{ }^{1} \mathrm{~A}_{1} \quad \begin{array}{c}
\text { For tetrahydrofuran (THF), we have } \\
\text { action }
\end{array} \\
\mathrm{C}_{4} \mathrm{H}_{4} \mathrm{O}\left(\mathrm{C}_{2 \mathrm{v}}, \tilde{\mathrm{X}}^{1} \mathrm{~A}_{1}\right)+\mathrm{H}_{2}\left(D_{\infty h}, \tilde{\mathrm{X}}^{1} \Sigma_{g}^{+}\right)+\mathrm{H}_{2}\left(D_{\infty h}, \tilde{\mathrm{X}}^{1} \Sigma_{g}^{+}\right) \rightarrow \mathrm{C}_{4} \mathrm{H}_{8} \mathrm{O}\left(\mathrm{C}_{2 \mathrm{v}}, \mathrm{C}_{\mathrm{s}}, \mathrm{C}_{2} \text { or } \mathrm{C}_{1}\right)
\end{gathered}
$$

Here, we only list these results by a table without the details of derivation.

The molecular property without indicating the symmetry and electronic state is meaningless. The electronic states derived here are proved by the following calculations.

\section{CALCULATION AND COMPARISON}

The present calculation is based on the density functional theory (DFT) described above and used the B3P86 method of Eq.9 with basis set 6-311G**.The calculated energy with B3P86 is usually the lowest one. The GAUSSIAN03 [20] package of program were employed to carry out all the calculations reported in this work.

The calculated geometry of $\mathrm{C}_{2 \mathrm{v}}$ is shown in Figure 1, where, 4 of carbon atoms $\mathrm{C}$ and oxygen atom $\mathrm{O}$ constitute a plane, i.e. $\sigma_{v}^{\prime}(y z)$ of $\mathrm{C}_{2 \mathrm{v}}$ and $\mathrm{C}_{2}$ is z-axis passing through oxygen atom $\mathrm{O}$ and bisecting the opposite bond C-C. The electronic state is ${ }^{1} \mathrm{~A}_{1}$ and triplet state ${ }^{3} \mathrm{~B}_{1}$ is in a high level by $6.569 \mathrm{eV}$ than ${ }^{1} \mathrm{~A}_{1}$. Each carbon atoms $\mathrm{C}$ is not to be $\mathrm{sp}^{2}$ hybridization, for each carbon atoms $\mathrm{C}$ has four bonds to connect four of atoms, then, it will be impossible to have plane structure. In addition, the lowest two of 33 harmonic frequencies $\left(\mathrm{cm}^{-1}\right)$ are negative, i.e. $\mathrm{B}_{1}=-222.7 ; \mathrm{A}_{2}=-207.4$ (To see the end of Table 1), this is an implicit assent of that $C_{2 v}$ geometry would be a transition state, which is agreement with reference [7-9]. This is why to have energy level sequence $\mathrm{C}_{1}<\mathrm{C}_{\mathrm{s}}<\mathrm{C}_{2 \mathrm{v}}$.

The calculated geometry of $\mathrm{C}_{\mathrm{s}}$ is shown in Figure 2, where, 4 of carbon atoms $\mathrm{C}$ and oxygen atom $\mathrm{O}$ are not on a plane, atom $\mathrm{O}$ out of this plane. This is similar to the envelope $C_{s}$ conformation [3]. The energy of $C_{s}$ is a little lower than that of $\mathrm{C}_{2 \mathrm{v}}$. The lowest two of 33 harmonic frequencies $\left(\mathrm{cm}^{-1}\right)$ are also negative, i.e. $\mathrm{A}^{\prime \prime}=-222.8$; $\mathrm{A}^{\prime \prime}$ $=-207.7$ (To see the end of Table 2). Therefore, $C_{s}$ would be a transition state, and is not a ground state which is contrary to that of [3].
And the resolution of ${ }^{1} D_{g}$ of $\mathrm{O}$ atom is

$$
{ }^{1} D_{g} \rightarrow \mathrm{C}_{2 \mathrm{v}}, 2{ }^{1} \mathrm{~A}_{1} \oplus{ }^{1} \mathrm{~A}_{2} \oplus{ }^{1} \mathrm{~B}_{1} \oplus{ }^{1} \mathrm{~B}_{2}
$$

The direct product will be

$$
\begin{aligned}
& { }^{1} \mathrm{~A}_{1} \otimes{ }^{1} \mathrm{~A}_{1} \otimes{ }^{1} \mathrm{~A}_{1} \otimes{ }^{1} \mathrm{~A}_{1} \otimes\left\{2{ }^{1} \mathrm{~A}_{1} \oplus{ }^{1} \mathrm{~A}_{2} \oplus{ }^{1} \mathrm{~B}_{1} \oplus{ }^{1} \mathrm{~B}_{2}\right\} \\
& =2^{1} \mathrm{~A}_{1} \oplus{ }^{1} \mathrm{~A}_{2} \oplus{ }^{1} \mathrm{~B}_{1} \oplus{ }^{1} \mathrm{~B}_{2}
\end{aligned}
$$

There will be component ${ }^{1} \mathrm{~A}_{1}$ for furan $\left(\mathrm{C}_{4} \mathrm{H}_{4} \mathrm{O}\right)$ i.e. the allowed electronic state.

For tetrahydrofuran (THF), we have the following re-

The calculated geometry of $\mathrm{C}_{1}$ is shown in Figure 3 and Table 3 . The energy of this state is lower by 0.16705 ev or $1347.3 \mathrm{~cm}^{-1}$ than that of $\mathrm{C}_{2 \mathrm{v}}$ with ${ }^{1} \mathrm{~A}_{1}$. The harmonic frequencies $\left(\mathrm{cm}^{-1}\right)$ for the $\mathrm{C}_{1}$ geometry are $\mathrm{A}=$ 53.91, $\mathrm{A}=266.1, \mathrm{~A}=576.1, \cdots, \mathrm{A}=3080, \mathrm{~A}=3113.8$ and $\mathrm{A}=3122.3$. Moreover, the important thing is no negative value only for this conformation, Therefore, the ground electronic state is $\tilde{\mathrm{X}}^{1} \mathrm{~A}$ for tetrahydrofuran (THF) in which 4 of carbon atoms $\mathrm{C}$ and oxygen atom $\mathrm{O}$ do not constitute a plane, but, like a "wave plane", or the "helix surface" as shown in Figure 3(c), where the hydrogen atoms have been neglected.

\section{CONCLUSION}

The calculations with method B3P86/6-311G** show that the energy level sequence is $E\left(\mathrm{C}_{1}, \tilde{\mathrm{X}}^{1} \mathrm{~A}\right)<$ $E\left(\mathrm{C}_{\mathrm{s}},{ }^{1} \mathrm{~A}^{\prime}\right)<E\left(\mathrm{C}_{2 \mathrm{v}},{ }^{1} \mathrm{~A}_{1}\right)$ for tetrahydrofuran (THF). Although the symmetry of $\mathrm{C}_{2 \mathrm{v}}$ is relatively high, the energy of $\left(C_{2 v},{ }^{1} A_{1}\right)$ is not the lowest, or the highest one. And there are two of negative harmonic frequencies. Therefore, the $\mathrm{C}_{2 \mathrm{v}}$ conformation with state ${ }^{1} \mathrm{~A}_{1}$ is probably a transition structure.

For $\mathrm{C}_{\mathrm{s}}$ conformation with state ${ }^{1} \mathrm{~A}^{\prime}$, there are also two of negative harmonic frequencies and it is not possible to be the equilibrium conformation of THF. This would be contrary to Reference [9].

The $\mathrm{C}_{1}$ symmetry with ground state $\left(\tilde{\mathrm{X}}^{1} \mathrm{~A}\right)$ is the equilibrium conformation of THF, we believe, for its energy is the lowest one and it is only possible without the negative harmonic frequency. In this conformation the 4 of carbon atoms $\mathrm{C}$ and oxygen atom $\mathrm{O}$ constitute a curved surface or the helix surface shown in Figure 3(c).

In the $\mathrm{C}_{2 \mathrm{v}}$ conformation, 4 of carbon atoms $\mathrm{C}$ and oxygen atom $\mathrm{O}$ all are on a plane, and for the $\mathrm{C}_{\mathrm{s}}$ conformation, 4 of carbon atoms $C$ are on a plane, both of them would be under the much molecular internal stress-strain, because of no $\mathrm{sp}^{2}$ hybridization for each carbon atoms $\mathrm{C}$ as described above. 
Table 1. The results of theoretical derivation for the possible electronic state of THF.

\begin{tabular}{lcc}
\hline \multicolumn{2}{c}{$\mathrm{C}_{4} \mathrm{H}_{4} \mathrm{O}\left(\mathrm{C}_{2 \mathrm{v}}, \tilde{\mathrm{X}}^{1} \mathrm{~A}_{1}\right)+\mathrm{H}_{2}\left(D_{\alpha h}, \tilde{\mathrm{X}}^{1} \Sigma_{g}^{+}\right)+\mathrm{H}_{2}\left(D_{\alpha h}, \tilde{\mathrm{X}}^{1} \Sigma_{g}^{+}\right) \rightarrow \mathrm{C}_{4} \mathrm{H}_{8} \mathrm{O}\left(\mathrm{C}_{2 \mathrm{v}}, \mathrm{C}_{\mathrm{s}}, \mathrm{C}_{2}\right.$ or $\left.\mathrm{C}_{1}\right)$} \\
\hline Resolution and direct product & ${ }^{1} \mathrm{~A}_{1} \otimes{ }^{1} \mathrm{~A}_{1} \otimes{ }^{1} \mathrm{~A}_{1}={ }^{1} \mathrm{~A}_{1}$ & for $\mathrm{C}_{4} \mathrm{H}_{8} \mathrm{O}\left(\mathrm{C}_{2 \mathrm{v}},{ }^{1} \mathrm{~A}_{1}\right)$ \\
Resolution and direct product & ${ }^{1} \mathrm{~A}^{\prime} \otimes{ }^{1} \mathrm{~A}^{\prime} \otimes{ }^{1} \mathrm{~A}^{\prime}={ }^{1} \mathrm{~A}^{\prime}$ & for $\mathrm{C}_{4} \mathrm{H}_{8} \mathrm{O}\left(\mathrm{C}_{\mathrm{s}},{ }^{1} \mathrm{~A}^{\prime}\right)$ \\
Resolution and direct product & ${ }^{1} \mathrm{~A} \otimes{ }^{1} \mathrm{~A} \otimes{ }^{1} \mathrm{~A}={ }^{1} \mathrm{~A}$ & for $\mathrm{C}_{4} \mathrm{H}_{8} \mathrm{O}\left(\mathrm{C}_{1},{ }^{1} \mathrm{~A}\right)$ \\
\hline
\end{tabular}

Table 2. The geometry of $\mathrm{C}_{2 \mathrm{v}}$ and $\mathrm{C}_{\mathrm{s}}$ for THF with method (B3P86/6-311G**).

\begin{tabular}{|c|c|c|}
\hline Electronic state & ${ }^{1} \mathrm{~A}_{1}$ & ${ }^{1} \mathrm{~A}^{\prime}$ \\
\hline Energy/a.u. & -233.2312368 & -233.2312369 \\
\hline \multicolumn{3}{|l|}{ Bond length/ $\AA$} \\
\hline $\mathrm{R}(1,4)=\mathrm{R}(4,5)$ & 1.4173 & 1.4172 \\
\hline $\mathrm{R}(1,2)=\mathrm{R}(4,3)$ & 1.5359 & 1.536 \\
\hline $\mathrm{R}(2,3)=$ & 1.5385 & 1.5387 \\
\hline $\mathrm{R}(1, \mathrm{H})=\mathrm{R}(4, \mathrm{H})$ & 1.096 & 1.0961 \\
\hline $\mathrm{R}(2, \mathrm{H})=\mathrm{R}(3, \mathrm{H})$ & 1.0914 & 1.0913 \\
\hline \multicolumn{3}{|l|}{ Bond angle $^{\circ}$} \\
\hline $\mathrm{A}(5,1, \mathrm{H})=\mathrm{A}(5,4, \mathrm{H})$ & 108.778 & 108.7578 \\
\hline $\mathrm{A}(1,5,4)$ & 112.2064 & 112.1817 \\
\hline $\mathrm{A}(2,1,5)=\mathrm{A}(3,4,5)$ & 108.5243 & 108.5573 \\
\hline $\mathrm{A}(\mathrm{H}, 1,2)=\mathrm{A}(\mathrm{H}, 4,3)$ & 111.5638 & 111.5653 \\
\hline $\mathrm{A}(\mathrm{H}, 2,3)=\mathrm{A}(\mathrm{H}, 3,2)$ & 111.24 & 111.187 \\
\hline $\mathrm{A}(1,2, \mathrm{H})=\mathrm{A}(4,3, \mathrm{H})$ & 111.0238 & 111.0333 \\
\hline $\mathrm{A}(\mathrm{H}, 1, \mathrm{H})=\mathrm{A}(\mathrm{H}, 4, \mathrm{H})$ & 107.5635 & \\
\hline $\mathrm{A}(\mathrm{H}, 3, \mathrm{H})=\mathrm{A}(\mathrm{H}, 2, \mathrm{H})$ & 107.012 & \\
\hline \multicolumn{3}{|l|}{ Electronic charge } \\
\hline $\mathrm{O}$ & -0.388101 & -0.388032 \\
\hline $1 \mathrm{C}=4 \mathrm{C}$ & 0.229799 & -0.035602 \\
\hline $2 C=3 C$ & -0.035748 & 0.229665 \\
\hline All H & 0.0000 & 0.0000 \\
\hline Dipole moment/ Debye & $1.8419 \mathrm{e}$ & 1.8424 \\
\hline E/KCal/Mol & 75.308 & 75.310 \\
\hline $\mathrm{C}_{\mathrm{V}} / \mathrm{Cal} / \mathrm{Mol}-\mathrm{K}$ & 12.917 & 12.919 \\
\hline S/Cal/Mol-K & 64.226 & 65.604 \\
\hline \multicolumn{3}{|l|}{ Harmonic frequencies $/ \mathrm{cm}^{-1}$ : } \\
\hline \multicolumn{3}{|l|}{ For $\mathrm{C}_{2 \mathrm{v}}: \mathrm{B}_{1}=-222.7 ; \mathrm{A}_{2}=-207.4 ; \ldots \mathrm{B}_{1}=3127$} \\
\hline For $\mathrm{C}_{\mathrm{s}}: \mathrm{A}^{\prime \prime}=-222.8 ; \mathrm{A} "=-207.7 ; \ldots \mathrm{A} "=3128$. & & \\
\hline
\end{tabular}

Notice: For the state ${ }^{3} \mathrm{~B}_{1}$, Energy $=-232.9898498 \mathrm{au}$.

As mentioned before, tetrahydrofuran (THF) molecule $\left(\mathrm{C}_{4} \mathrm{H}_{8} \mathrm{O}\right)$ can be as a simple prototype of deoxyribose and has been reviving a quite deal of interest in radiation damage research. It is well known that the sugar ring of deoxyribose is considered as a plane in most of the references such as [21]. If the equilibrium conformation of THF is $\mathrm{C}_{1}$ symmetry with the helix surface, and the sugar ring of deoxyribose would be the helix surface, this 
Table 3. The geometry of $\mathrm{C}_{1}$ for THF with method (B3P86/6-311G**).

\begin{tabular}{lc}
\hline Electronic state $\tilde{\mathrm{X}}^{1} \mathrm{~A}$, Energy $=-233.2373758$ a.u. & \\
\hline Bond length $\AA$ & Bond angle ${ }^{\circ}$ \\
$\mathrm{R}(1,2)=1.4252$ & $\mathrm{~A}(2,1,5)=106.3103$ \\
$\mathrm{R}(2,3)=1.425$ & $\mathrm{~A}(2,3,4)=106.3032$ \\
$\mathrm{R}(1,5)=1.5243$ & $\mathrm{~A}(3,4,5)=101.3314$ \\
$\mathrm{R}(3,4)=1.5243$ & $\mathrm{~A}(1,5,4)=101.3388$ \\
$\mathrm{R}(4,5)=1.5267$ & $\mathrm{D}(5,1,2,3)=-12.3443$ \\
$\mathrm{R}(4,10)=\mathrm{R}(5,13)=1.0916$ & $\mathrm{D}(2,1,5,4)=31.6173$ \\
$\mathrm{R}(4,11)=\mathrm{R}(5,12)=1.0942$ & $\mathrm{D}(1,2,3,4)=-12.4637$ \\
$\mathrm{R}(1,7)=\mathrm{R}(3,9)=1.0934$ & $\mathrm{D}(2,3,4,5)=31.6873$ \\
$\mathrm{R}(1,6)=\mathrm{R}(3,8)=1.0986$ & \\
Electronic charge & $\mathrm{E}=76.361 \mathrm{KCal} / \mathrm{Mol}$ \\
$2 \mathrm{O}=-0.678023$ & $\mathrm{C} \mathrm{V}=16.891 \mathrm{Cal} / \mathrm{Mol}-\mathrm{K}$ \\
$1 \mathrm{C}=3 \mathrm{C}=0.347631$ & $\mathrm{~S}=71.996 \mathrm{Cal} / \mathrm{Mol}-\mathrm{K}$ \\
$4 \mathrm{C}=-0.008654$ & \\
$5 C=-0.008670$ & \\
Dipole moment $=1.8115$ Debye & \\
Harmonic frequencies $\left(\mathrm{cm}^{-1}\right):$ & \\
$\mathrm{A}=53.91, \mathrm{~A}=266.1, \mathrm{~A}=576.1, \ldots, \mathrm{A}=3080, \mathrm{~A}=3113.8, \mathrm{~A}=3122.3$ & \\
\hline
\end{tabular}

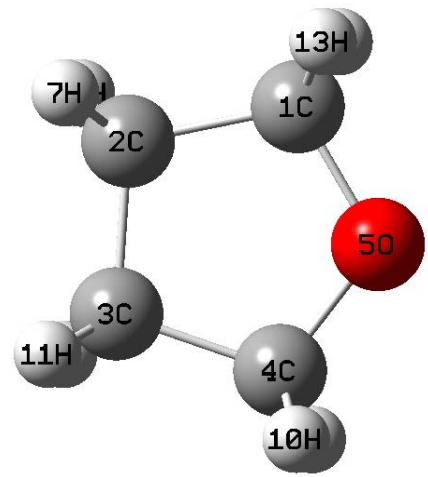

(a)

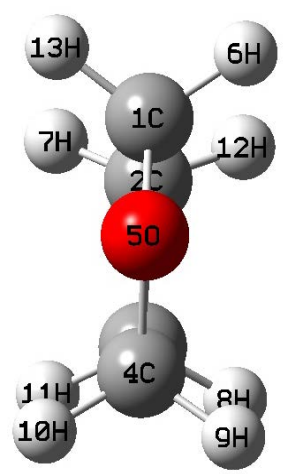

(b)

Figure 1. The schematic drawing of geometry for $\operatorname{THF}\left(\mathrm{C}_{2 \mathrm{v}}, \mathrm{A}_{1}\right)$ : (a) Top view; (b) Side view.

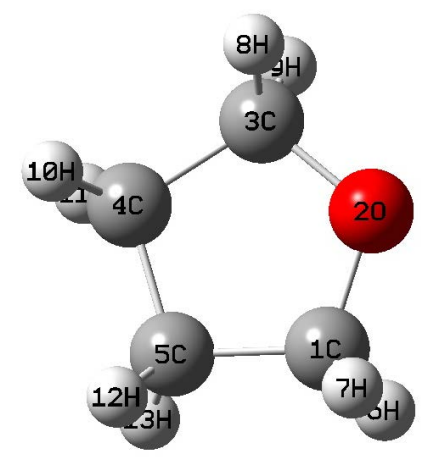

(a)

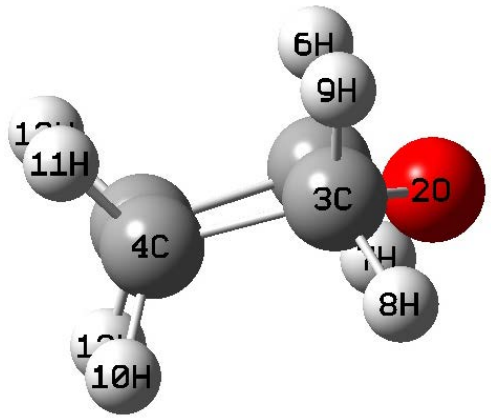

(b)

Figure 2. The schematic drawing of geometry for THF $\left(\mathrm{C}_{\mathrm{s}},{ }^{1} \mathrm{~A}^{\prime}\right)$ : (a) Top view; (b) Side view. 


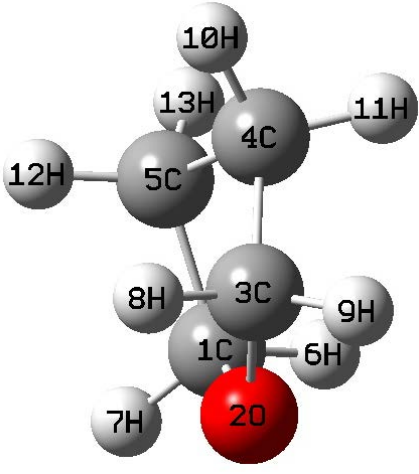

(a)

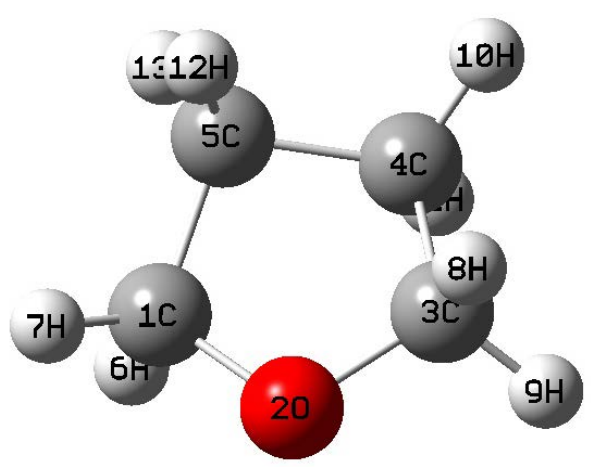

(b)

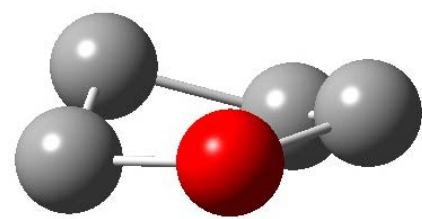

(c)

Figure 3. The schematic drawing of geometry for THF $\left(\mathrm{C}_{1}, \tilde{X}^{1} \mathrm{~A}\right)$ : (a) Side view; (b) Top view; (c) the helix surface where all the hydrogen atoms neglected.

probably causes the double helix of DNA. It is hardly believed that the sugar ring is a plane in deoxyribose ring. Many of properties for molecular biology, for example, the sugar moiety itself in DNA being active in the initial molecular processes leading to single strand breaks, have been studied [22], however, there are a few researches on the molecular level.

\section{ACKNOWLEDGEMENTS}

This work is supported by the Natural Science Foundation of Hainan (Grant No.110001).

\section{REFERENCES}

[1] Boudaiffa, B., Cloutier, P., Hunting, D., et al. (2000) Resonant formation of DNA strand breaks by low-energy (3 to $20 \mathrm{eV}$ ) electrons. Science, 287, 1658-1660. http://dx.doi.org/10.1126/science.287.5458.1658

[2] Lepage, M., Letarte, S., Michaud, M., et al. (1998) Electron spectroscopy of resonance-enhanced vibrational excitations of gaseous and solid tetrahydrofuran. Journal of Chemical Physics, 109, 5980-5986. http://dx.doi.org/10.1063/1.477223

[3] Antic, D., Parenteau, L., Lepage, M., et al. (1999) Lowenergy electron damage to condensed-phase deoxyribose analogues investigated by electron stimulated desorption of $\mathrm{H}^{-}$and electron energy loss spectroscopy. Journal of Chemical Physics B, 103, 6611-6619. http://dx.doi.org/10.1021/jp9906861

[4] Antic, D., Parenteau, L. and Sanche, L. (2000) Electronstimulated desorption of $\mathrm{H}^{-}$from condensed phase deoxyrib ose analogues: Dissociative electron attachment versus resonance decay into dipolar dissociation. Journal of Chemical Physics B, 104, 4711-4716. http://dx.doi.org/10.1021/jp000206m

[5] Breton, S.-P., Michaud, M., Jaggle, C., et al. (2004) Damage induced by low-energy electrons in solid films of tetrahydrofuran. Journal of Chemical Physics, 121, 1124011249. http://dx.doi.org/10.1063/1.1814632
[6] Watson, J.D. and Crick, F.H.C. (1953) Molecular structure of nucleic acids, a structure for deoxyribose nucleic acid. Nature, 171, 737-738. http://dx.doi.org/10.1038/171737a0

[7] Mamleev, A.H., Gunderova, L.N. and Gallev, R.V. (2001) Microwave spectrum and hindered pseudorotation of tetrahydrofuran. Journal of Structural Chemistry, 42, 365370. http://dx.doi.org/10.1023/A:1012448618502

[8] Melnik, D.G., Gopalakrishnan, S., Miller, T.A., et al. (2003) The absorption spectroscopy of the lowest pseudorotational states of tetrahydrofuran. Journal of Chemical Physics, 118, 3589-3599. http://dx.doi.org/10.1063/1.1538241

[9] Victor, M.R. and Jose, A.S. (2005) Pseudorotation motion in tetrahydrofuran: An ab initio study. Journal of Chemical Physics, 122, 204303-1-8.

[10] Bowron, D.T., Finney, J.L. and Soper, A.K. (2006) The structure of liquid tetrahydrofuran. Journal of the American Chemical Society, 128, 5119-5126. http://dx.doi.org/10.1021/ja0583057

[11] Wang, R., Zhong, Q.L., Wu, R., et al. (2008) Molecular interactions between pyrazine and n-propanol, chloroform, or tetrahydrofuran. Spectrochimica Acta, Part A, 70, 793798. http://dx.doi.org/10.1016/j.saa.2007.09.014

[12] Yoshiharu, S. (2004) Evidence of pressure-induced amorphization of tetrahydrofuran clathrate hydrate. Physical Review B, 70, 172108-1-4.

[13] Becke, A.D. (1988) Density-functional exchange-energy approximation with correct asymptotic behavior. Physical Reviews, 38, 3098-3100. http://dx.doi.org/10.1103/PhysRevA.38.3098

[14] Perdew, J.P. and Wang, Y. (1992) Accurate and simple analytic representation of the electron-gas correlation energy. Physical Reviews B, 45, 13244-13249. http://dx.doi.org/10.1103/PhysRevB.45.13244

[15] Becke, A.D. (1993) Density functional thermo chemistry III, the role of exact exchange. Journal of Chemical Physics $B, \mathbf{9 8}, 5648-5652$.

[16] Zhu, Z.H. (1985) The general principle for determining the "microscopic" processes involving diatomic moleculeions. In the Page 14-15 of Takayanagi K. Atomic and Mo- 
lecular Physics (Japanese). The Institute of Space and Astronautically Science, Tokyo.

[17] Zhu, Z.H. (2007) Atomic and molecular reaction statics. Science in China Series G, 50, 581-590. http://dx.doi.org/10.1007/s11433-007-0054-6

[18] Zhu, Z.H. (2007) Atomic and molecular reaction statics. Science Press, Beijing.

[19] Klumpp, G.W. (1982) Reactivity in organic chemistry. A
Wiley-Interscience Publication.

[20] Frisch, M.J., Trucks, G.W., Schlegel, H.B., et al. (2003) Gaussian03. Gaussian, Inc., Pittsburgh.

[21] Cheng, C.X. (1998) Biophysical chemistry. Science and Technology Press, Beijing, 387.

[22] Philipp, S., Sylwia, P., Fabio, Z., et al. (2006) Dissociative electron attachment to furan, tetrahydrofuran, and fructose. Journal of Chemical Physics, 125, 044304-1-6. 